Rev Inv Vet Perú 2004; 15 (1): 70-75

\title{
SEROPREVALENCIA DE Neospora caninum EN PERROS DE ESTABLOS LECHEROS DE LA CUENCA IZQUIERDA DEL VALLE DEL MANTARO
}

\author{
Nathann Cornejo P. ${ }^{1}$, Amanda Chávez V. ${ }^{2,3}$, Eva Casas A. ${ }^{2}$ y Carlos Arana D. ${ }^{4}$
}

The neosporosis is an emergent disease, and considered as an important cause of abortion in cattle and a cause of neuromuscular disorders in dogs. The aim of the present study was to determine the seroprevalence of Neospora caninum in dogs of dairy farms in the left zone of the valley of Mantaro. A total of 24 serum samples of dogs living in and in the vicinity of 24 dairy farms of the provinces of Huancayo, Jauja and Concepcion were evaluated. The seroprevalence of antibodies against $N$. caninum was $19.4 \pm 7.0 \%$ $(24 / 124)$ in a dilution of 1:50, using the indirect immunofluorescense test. The percentage of farms having at least one infected dog was $62.5 \%$ (15/24). Statistical relationships between the rate of infection and the geographical location (province), age, sex, and origin (in and closeby the farm) did not exist. These results showed that dogs in the valley of Mantaro presented a moderate seroprevalence of $N$. caninum; and considering that the infection is present in most dairy farms of the valley, is recommended to limit the access of dogs to dairy farms in the valley.

Key words: neosporosis, dogs, seroprevalence, IFAT, dairy farms

\section{RESUMIEN}

La neosporosis es una enfermedad emergente, considerada causa importante de aborto en el ganado bovino y de procesos neuromusculares graves en perros. El objetivo del presente estudio fue determinar la seroprevalencia de Neospora caninum en perros de establos lecheros de la cuenca izquierda del valle del Mantaro. Se evaluaron 124 sueros de perros, provenientes de 24 establos lecheros de las provincias de Huancayo, Jauja y Concepción. Se halló una prevalencia de anticuerpos contra $N$. caninum de 19.4 $\pm 7.0 \%$ (24/124), en una dilución de 1:50, mediante la prueba de inmunofluorescencia indirecta. El porcentaje de establos que poseían al menos un perro infectado fue de $62.5 \%$ $(15 / 24)$. No se halló asociación entre la tasa de infección y las variables ubicación geográfica (provincia), edad, sexo y procedencia (en el establo o en los alrededores). Estos resultados demuestran que los caninos del valle del Mantaro presentan una prevalencia moderada de infección con $N$. caninum; y considerando que dicha infección está presente en la mayoría de los establos de la zona, se recomienda el control del acceso de los canes a los establecimientos lecheros en el valle del Mantaro.

Palabras clave: neosporosis, perros, seroprevalencia, IFI, establos lecheros

\footnotetext{
${ }^{1}$ Práctica privada

${ }^{2}$ Laboratorio de Microbiología y Parasitología Veterinaria, FMV-UNMSM

${ }^{3}$ E-mail: a_chavez_g@hotmail.com

${ }^{4}$ Estación Experimental del Centro de Investigaciones IVITA-El Mantaro, FMV-UNMSM
} 


\section{INTRODUCCIÓN}

Desde el descubrimiento del Neospora caninum a fines de la década del ochenta, su importancia ha ido en aumento debido a los problemas reproductivos que ocasiona en los bovinos. La neosporosis es una parasitosis reportada en un gran número de especies domésticas y silvestres que ocasiona problemas neuromusculares en perros (Dubey y Lappin, 2000). Actualmente, en el ganado lechero el $N$. caninum es considerado como una de las principales causas de aborto y por lo tanto, tiene una gran repercusión económica.

Hasta 1998 se conocía poco sobre la transmisión de este parásito. McAllister et al. (1998) determinaron su ciclo de vida y demostraron que el hospedero definitivo es el perro. Así, la cercanía del perro con los bovinos lecheros lo evidencian como fuente potencial de transmisión. Por otro lado, recientemente se considera al $N$. caninum como agente primario de enfermedad neuromuscular en perros jóvenes. La infección en los canes ha sido reportada en varios países, aunque los casos de enfermedad clínica son escasos. Estudios epidemiológicos demuestran que los perros presentan prevalencias variadas, sin embargo, los perros de zonas urbanas presentan una tasa de infección menor que aquellos que viven en establos; y además dicha infección aumenta cuando los animales proceden de establos con problemas de abortos (Basso et al., 1999).

En el Perú se ha reportado la infección con $N$. caninum en fetos abortados (Rivera, 2001) y en vacas con antecedentes de aborto (Rivera et al., 2000) por lo que este parásito es considerado un agente causante de abortos en bovinos en el país. Además, la infección ha sido demostrada en vacas y perros de establos lecheros en las provincias de Lima y Chachapoyas (Del Campo et al., 2003; Horna et al., 2003) y en otras cuencas lecheras importantes. La presencia de $N$. caninum ha sido demostrada en vacas del valle del Mantaro (E. Casas, comunicación personal) pero la fuente de infección no ha sido identificada. El objetivo del presente estudio fue determinar la prevalencia de la infección en perros del valle del Mantaro.

\section{Materiales y Métodos}

El estudio se realizó en la cuenca izquierda del valle del Mantaro (provincias de Jauja, Concepción y Huancayo) del departamento de Junín, durante los meses de agosto a octubre del 2002.

Se tomaron muestras de sangre a perros. El suero se obtuvo por centrifugación a 3, 000 rpm por 5 minutos. El tamaño muestral (número de perros) fue calculado usando la fórmula para estimar una proporción (Daniel, 1996). Se utilizó como referencia la prevalencia de $28.9 \%$ de anticuerpos contra $N$. caninum en perros del distrito de Chachapoyas (Horna, 2003), con un nivel de confianza de $90 \%$ y un error máximo admisible de $0.07 \%$. El tamaño muestral resultante ( $\mathrm{n}=109)$ representa el número mínimo de animales a muestrearse. Además, se evaluó la asociación de las variables ubicación geográfica (provincia), edad, sexo y procedencia (perros que viven dentro o alrededor del establo) con la tasa de infección mediante la prueba de chi-cuadrado (González y Falcón, 1999).

Los anticuerpos contra Neospora caninum fueron determinados mediante la prueba de inmunofluorescencia indirecta (IFI) a una dilución de 1:50. Las muestras se consideraron positivas al observar la fluorescencia en todo el contorno del taquizoíto y negativas si no hubo fluorescencia o ésta fue parcial.

\section{Resultados}

La prevalencia de anticuerpos contra Neospora caninum en 124 muestras de sue- 
Cuadro 1. Seroprevalencia de Neospora caninum en caninos relacionados con establos lecheros del departamento de Junín. 2002

\begin{tabular}{|c|c|c|c|c|c|}
\hline & & \multirow{2}{*}{$\begin{array}{l}\mathrm{N}^{\mathrm{o}} \mathrm{de} \\
\text { establos }\end{array}$} & \multicolumn{2}{|c|}{$\mathrm{N}^{\circ}$ de animales } & \multirow{2}{*}{$\begin{array}{c}\text { Seroprevalencia } \\
\% ? \text { IC }^{1}\end{array}$} \\
\hline & & & Muestreados & Positivos & \\
\hline \multicolumn{6}{|c|}{ Provincias } \\
\hline & Huancayo & 10 & 53 & 9 & $17.0 ? 10.1$ \\
\hline & Jauja & 9 & 41 & 6 & $14.6 ? 10.8$ \\
\hline & Concepción & 5 & 30 & 9 & $30.0 ? 16.4$ \\
\hline \multicolumn{6}{|c|}{ Edad } \\
\hline & $<1$ & & 17 & 1 & $5.9 ? 23.4$ \\
\hline & 1 - 2 años & & 61 & 11 & $18.0 ? 9.7$ \\
\hline & 3 - 4 años & & 26 & 6 & $23.1 ? 16.2$ \\
\hline & 5 - 6 años & & 12 & 3 & $25.0 ? 24.5$ \\
\hline & $? 7$ & & 8 & 3 & $37.5 ? 33.6$ \\
\hline \multicolumn{6}{|c|}{ Sexo } \\
\hline & Macho & & 70 & 18 & $25.7 ? 10.2$ \\
\hline & Hembra & & 54 & 6 & $11.1 ? 8.4$ \\
\hline \multicolumn{6}{|c|}{ Ubicación } \\
\hline & Del establo & & 84 & 18 & $21.4 ? 8.8$ \\
\hline & De alrededor & & 40 & 6 & $15.0 ? 11.1$ \\
\hline Total & & 24 & 124 & 24 & $19.4 ? 7.0$ \\
\hline
\end{tabular}

${ }^{1}$ Intervalo de confianza del $95 \%$

Cuadro 2. Análisis de asociación de la tasa de infección con Neospora caninum con las variables provincia, edad, sexo y procedencia de caninos de establos lecheros del departamento de Junín. 2002

\begin{tabular}{lccc}
\hline Variables & $\mathrm{X}^{2}{ }_{\mathrm{c}}$ & $\mathrm{X}_{\mathrm{t}}{ }$ & Significancia \\
\hline Provincia & 0.319 & 5.99 & 0.8530 \\
Grupo etáreo & 2.851 & 7.81 & 0.0523 \\
Sexo & 2.869 & 3.84 & 0.0900 \\
Procedencia & 0.4945 & 3.84 & 0.4820 \\
\hline
\end{tabular}


ros de caninos provenientes de 24 establos lecheros del valle del Mantaro fue de $19.4 \pm$ $7.0 \%$. El $62.5 \%(15 / 24)$ de los establos tenían al menos un animal infectado. La provincia de Concepción mostró una prevalencia relativa mayor (30\%) a la encontrada en las provincias de Jauja y Huancayo (14.6 y $17.0 \%$, respectivamente, Cuadro 1). Los animales menores de un año presentaron la prevalencia más baja (5.9\%), incrementándose con la edad, donde los animales con ?7 años presentaron la prevalencia más alta $(37.5 \%)$. Los machos presentaron una tasa de infección mayor a la encontrada en las hembras (25.7 vs. $11.1 \%$, respectivamente). Asimismo, los perros de establos presentaron una tasa de infección ligeramente superior (21.4\%) a la encontrada en perros de los alrededores $(15.0 \%)$. El análisis de variables mostró que la provincia, edad, género y procedencia de los animales no presentó asociación con la tasa de infección (Cuadro 2).

\section{Discusión}

La prevalencia de anticuerpos contra $N$. caninum encontrada de $19.4 \pm 7 \%$ y el $62.5 \%$ de establos que poseían al menos un perro infectado demuestra que la infección se encuentra presente en la mayoría de establos y extendida a lo largo de todo el valle del Mantaro. Estudios similares realizados en perros de otras zonas ganaderas del Perú, como los alrededores de Lima y la provincia de Chachapoyas, indicaron seroprevalencias del 33 y 29\% respectivamente (Del Campo et al., 2003; Horna et al., 2003), valores que fueron superiores al encontrado en el valle del Mantaro.

Aparentemente, existe una correlación entre la seroprevalencia de la infección con $N$. caninum de los bovinos con la de caninos. Así lo indican los resultados encontrados en bovinos del valle de Lima (29.6\%; Silva et al., 2002) y de Chachapoyas $(40.4 \%$; Quevedo et al., 2003) que mostraron una seroprevalencia moderadamente alta y con- cordante con las seroprevalencias encontradas en los caninos para el valle de Lima y en Chachapoyas (Del Campo et al., 2003; Horna et al., 2003). Por otro lado, Basso et al.(1999) reporta relaciones similares en la Argentina.

En el presente estudio, los resultados indican una seroprevalencia moderada $(19.4 \%)$, cuyo valor es similar a la prevalencia hallada en vacunos en esta misma cuenca $(18.2 \%$; E. Casas, comunicación personal). Estos datos apoyan la hipótesis de la transmisión horizontal entre bovinos y caninos; la que se facilitaría por las características de la explotación lechera de la zona, donde las instalaciones son de tipo semi extensivo y la alimentación es al pastoreo, en campos de fácil acceso para los perros.

En otros países, la prevalencia obtenida en este tipo de estudio fue variable; así, en perros de centros ganaderos de Uruguay (Barber et al., 1997) se obtuvo prevalencias similares a este estudio (20\%), mientras que en otras latitudes los resultados fueron superiores: 31,36 y $73 \%$ en perros de establos lecheros de Japón (Sawada et al., 1998), Brasil (Belo et al., 1999) y Argentina (Basso et al., 1999), respectivamente; aunque es importante indicar que en estos estudios no se correlacionaron los resultados de caninos con prevalencias en bovinos.

No se encontraron diferencias estadísticas por efecto de la ubicación geográfica. Sin embargo, Cheadle et al. (1999) y Wouda et al. (1999) encontraron diferencias significativas en la tasa de infección en diferentes zonas geográficas, atribuyéndolas a las variaciones locales de la temperatura. Estas diferencias de temperatura en las provincias evaluadas en el valle del Mantaro son mínimas, lo que podría indicar que las diferencias encontradas se deban al azar.

Las divergencias de prevalencias por efecto de la edad de los perros se deberían mayormente a la mayor posibilidad que los perros de más edad se infecten al haber estado más tiempo con los vacunos y sugieren 
además una exposición post-parto; sin embargo, al analizar esta variable, no se halló asociación estadística significativa entre los grupos etáreos con la tasa de infección. La literatura confirma que no hay influencia de la edad en la infección por $N$. caninum (Pereira-Bueno et al., 1999; Del Campo et al., 2003; Horna et al., 2003). Similarmente, pese a que los machos presentaron una prevalencia mayor que las hembras (25.7 vs. $11.1 \%$ ), no se halló asociación de esta variable con la infección. Estudios anteriores muestran resultados similares y señalan que el sexo no es un factor de riesgo para la infección (Del Campo et al., 2003; Horna et al., 2003).

Los perros que vivían en los establos presentaron una mayor seroprevalencia que los perros que vivían en los alrededores (21vs. $15 \%$, respectivamente). Estos resultados concuerdan con aquellos encontrados en Japón, Chile y Perú (Sawada et al., 1998; Patitucci et al., 2001; Horna et al., 2003); debido posiblemente a que los perros de los establos están en contacto permanente con el ganado y tienen una mayor posibilidad de infección que los perros de los alrededores. Además, estos perros son utilizados como pastores y para el cuidado del ganado por las noches. Sin embargo, no se demostró asociación entre esta características y el porcentaje de infección, de allí que las diferencias se deberían sólo a la mayor posibilidad de los perros a infectarse con $N$. caninum al estar más cerca del ganado bovino.

Ningún animal muestreado presentó signos clínicos de neosporosis. La presencia de anticuerpos contra $N$. caninum en el suero sólo demuestra infección pero no enfermedad (Dubey, 2003). Los estudios de seroprevalencia en perros han indicado que existe una mayor cantidad de animales con infección subclínica que animales con enfermedad (Dubey y Lappin, 2000). A pesar de esto, la neosporosis debe ser considerada como diagnóstico diferencial en perros con sintomatología nerviosa.
La fuente de infección en los perros aún no está clara. De manera eficaz, se ha reproducido la infección experimentalmente con tejidos de ratones y de terneros, pero el rango de hospederos intermediarios puede ser muy amplio (Ortega-Mora et al., 2001). Los perros del valle de Mantaro, tanto de los establos como de los alrededores, tienen acceso libre a los potreros y corrales de los bovinos, permitiendo que la posibilidad de transmisión horizontal sea alta. No obstante que la infección post-natal en los bovinos se encuentre dentro del rango de 2-5\% (Ortega y Mora et al., 2001), se deberían tomar medidas de control adecuadas que eviten su incremento, ya que la infección en los vacunos lecheros es muy difícil de erradicar luego de que ingresa en el rebaño.

Las medidas de control y prevención deben incluir pruebas serológicas a todo animal que ingrese al fundo, separar a las vacas durante el parto para evitar que los perros se alimenten de la placenta y loquios, y controlar el acceso de perros a las áreas de los bovinos.

\section{Literatura Citada}

1. Barber, S.; B. Gasser; J. Ellis; P. Reichel; D. McMillan; J. Trees. 1997. Prevalence of antibodies to Neospora caninum in different canid populations. J. Parasitol. 83: 1056-1058.

2. Basso, W.; L. Venturi; M. Rambeaud; J. Uazaga; D. Bacigalupe. 1999. Prevalencia de infección por Neospora caninum en perros de ciudad y del tambo. XIV Congreso Latinoamericano de Parasitología. Acapulco, México. p 90.

3. Belo, M.; P. Rezende; K. Catagnolli; K. Bresciani; A. Costa. 1999. Pesquisa de anticorpos anti-Nesopora caninum em cães criados sob diferentes condições sanitarias. XI Seminario Brasileiro de Parasitología Veterinaria. Salvador. p 228. 
4. Cheadle, M.; J. Spencer; B. Blackburn. 1999. Seroprevalence of Neospora caninum and Toxoplasma gondii in non-domestic felids from Southern Africa. J. Zoo Wildlife Med. 30: 248-251.

5. Daniel, W. 1996. Bioestadística: Base para el análisis de las ciencias de la salud. $3^{\text {a }}$ ed. p 202-209. Limusa. México.

6. Del Campo, J.; A. Chávez; A. Delgado; N. Falcón; A. Ornelas; E. Casas; E. Serrano. 2003. Frecuencia de Neospora caninum en perros de establos lecheros del valle de Lima. Rev. Inv. Vet. Perú 14: 145-149.

7. Dubey, J.; M. Lappin. 2000. Neosporosis. En: Enfermedades infecciosas en perros y gatos. $2^{\mathrm{a}}$ ed. Greene, C. (ed). Mac Graw Hill-Interamericana. México. p 554-560.

8. Dubey, J. 2003. Review of Neospora caninum and neosporosis in animals. Korean J. Parasitol. 41: 1-16.

9. González, A.; N. Falcón. 1999. Análisis de datos en medicina veterinaria. Pub. Tec. Facultad de Medicina Veterinaria, Univ. Nacional Mayor de San Marcos. Lima Perú. p 41-59.

10. Horna, S.; A. Chávez; E. Casas; E. Serrano. 2003. Seroprevalencia de Neospora caninum en caninos de dos distritos de la provincia de Chachapoyas. Rev. Inv. Vet. Perú 14: 150-154.

11. McAllister, M.; J. Dubey; D. Lindsay; W. Jolley; R. Wills; A. McGuire. 1998. Dogs are definitive hosts of Neospora caninum. Int. J. Parasitol. 28: 1473-1478.

12. Ortega-Mora, L.; E. Collantes; G. Álvarez. 2001. La neosporosis del ganado bovino: una enfermedad emergente. Rev. Cien. Vet. Perú. 17: 7-14.
13. Patitucci, A.; M. Pérez; M. Rozas; K. Israel. 2001. Neosporosis canina: presencia de anticuerpos séricos en poblaciones caninas rurales y urbanas de Chile. Arch. Med. Vet. Chile 33: 227-232.

14. Pereira-Bueno, J.; A. QuintanillaGozalo; L. Del Río-Gonzales; L. Ortega-Mora. 1999. Epidemiología (II): transmisión y factores de riesgo. Bovis 88: 35-42.

15. Quevedo, J.; A. Chávez; H. Rivera; E. Casas; E. Serrano. 2003. Neosporosis en bovinos lecheros en dos distritos de la provincia de Chachapoyas. Rev. Inv. Vet. Perú 14: 33-37.

16. Rivera, H.; D. Nelson; L. Tabacchi. 2000. Neospora caninum y otros agentes en fetos abortados de bovinos lecheros del Valle de Lima. Rev. Inv. Vet., Perú 11:1-7.

17. Rivera, H. 2001. Etiología infecciosa del aborto bovino. Rev. Inv. Vet., Supl 1: 95-99.

18. Sawada M.; C. Park; H. Kondo; T. Morita; A. Shimada; I. Yamane; T. Umemura. 1998. Serological survey of antibody to Neospora caninum in Japanese dogs. J. Vet. Med. Sci. 60: 853-854.

19. Silva, P.; A. Chávez; H. Rivera; E. Casas. 2002. Seroprevalencia de Neospora caninum en bovinos lecheros del Valle de Lima. Rev. Inv. Vet. Perú 13: 51-55.

20. Wouda, W; T. Dijkstra; H. Kramer; C. Van Maanen; A. Brinkhof. 1999. Seroepidemiological evidence for a relationship between Neospora caninum infections in dogs and catle. Int. J. Parasitol. 29: 1677-1682. 